\title{
Correction to: Effects of the morphology of sediment-transporting channels on the erosion and deposition of debris flows
}

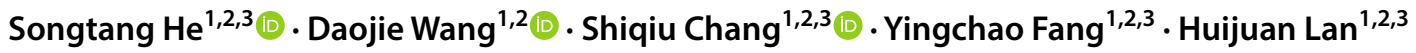

Published online: 29 August 2018

○) Springer-Verlag GmbH Germany, part of Springer Nature 2018

\section{Correction to: Environmental Earth Sciences (2018) 77:544 https://doi.org/10.1007/s12665-018-7721-y}

In the original publication, the reference "Gregoretti C, Fontana GD (2008) The triggering of debris flow due to channel-bed failure in some alpine headwater basins of the Dolomites: analyses of critical runoff. Hydrol Process 22(13):2248-2263" is published wrong.
The correct version of the reference is "Gregoretti C. and Dalla Fontana G. (2008) The triggering of debris flows due to channel-bed failure in some alpine headwater basins of Dolomites: analyses of critical runoff. Hydrological Processes, vol. 22, https://doi.org/10.1002/hyp.6821, pag. 2248-2263".

The original article can be found online at https://doi.org/10.1007/ s12665-018-7721-y.

Daojie Wang

wangdj@imde.ac.cn

Songtang $\mathrm{He}$

hst1529568372@126.com

Shiqiu Chang

shiqiu7@163.com

Yingchao Fang

1176988203@qq.com

Huijuan Lan

2692332976@qq.com

1 Key Laboratory of Mountain Hazards and Earth Surface Processes, Chinese Academy of Sciences, Chengdu 610041, China

2 Institute of Mountain Hazards and Environment, Chinese Academy of Sciences, \#.9, Block4, Renminnanlu Road, Chengdu 610041, China

3 University of Chinese Academy of Sciences, 100049 Beijing, China 